\title{
A comparative study on regression model and artificial neural network for the prediction of wall temperature in a building
}

DOI:10.36909/jer.ACMM.16317

\author{
Aishwarya $\mathbf{S}^{1}$, Balasubramanian $\mathbf{M}^{2 *}$ \\ ${ }^{1,2^{*}}$ Department of Civil Engineering, SRM Institute of Science and Technology, \\ Kattankulathur, Chennai India \\ Corresponding Author Email Id: balamv86@gmail.com
}

\begin{abstract}
This paper demonstrates the validation and prediction of the wall temperature of a building exposed to a composite climate. Two artificial intelligence models, such as multiple linear regression and artificial neural networks, have been used to predict. The wall temperature has been predicted mainly based on the parameters like ambient temperature, wind speed and relative humidity in all four directions of the buildings. Three statistical analyses were used to validate the model's outcome: R-Squared, Root Mean Square Error (RMSE) and Mean Absolute Error (MAE). In terms of train and control data, the two models yield comparable findings. The artificial neural network model has more adaptability since it was able to adjust to unexpected changes in the input data, according to a comparison of the applied mathematics of each model. The regression model was used for this investigation because it gives constant estimate values for the factors, though the neural model isn't numerically characterized. The review infers that the neural model must be utilized as an additional way to predict the wall temperature. This study can plan and adapt buildings for future work, considering the most critical climatic conditions. It also assists architects and engineers in determining the appropriate insulation for the building envelope, which improves its thermal performance.
\end{abstract}

Key words: Artificial neural network, Multiple linear regression, Statistical analysis, Wall temperature prediction, Thermal behaviour

\section{INTRODUCTION}

Global climate change is among essential concerns that have recently attracted much attention and investigation; it poses a significant risk to our system (McMichael and Lindgren 2011). The Intergovernmental Panel on Climate Change (IPCC) has proven that greenhouse gas emissions are caused by human activity with a $90 \%$ probability (Coley and Kershaw 
2010). Global climate change and unstable weather conditions directly or indirectly impact the building's energy and luxury needs. In a dynamic climate, the house's energy requirement increases together for heating and cooling increases (Chan 2011) (Nikolopoulou, Baker, and Steemers 2001). Over the past decade, demand for thermal comfort has grown thanks to the effects of urban heat and climate change (Arnfield 2003) (Spagnolo and de Dear 2003). On account of energy security and environmental concerns, researchers worldwide are attempting to expand the energy efficiency of the prominent structure by determining the climatic factors that significantly affect the structure's behaviour. Meteorological conditions, corresponding to the air temperature and radiation in the vicinity, often vary. A portion of the heat that enters the structure envelope can be trapped or retained by the access gathering, raising the wall's temperature.

This demonstrates that climatic variables substantially impact the outcome of the associate grade study evaluating the consequences of a building's thermal performance (Verbeke and Audenaert 2018). Each building's heat transport methods are primarily represented by the processes of conduction, convection, and radiation. A multi-variate analysis is employed as an irreversible process in this sort of sophisticated system, according to the heat flow in the building, in which the output parameters are utilized to analyse, evaluate, and adjust the input parameters (climatic conditions).

\section{LITERATURE STUDY}

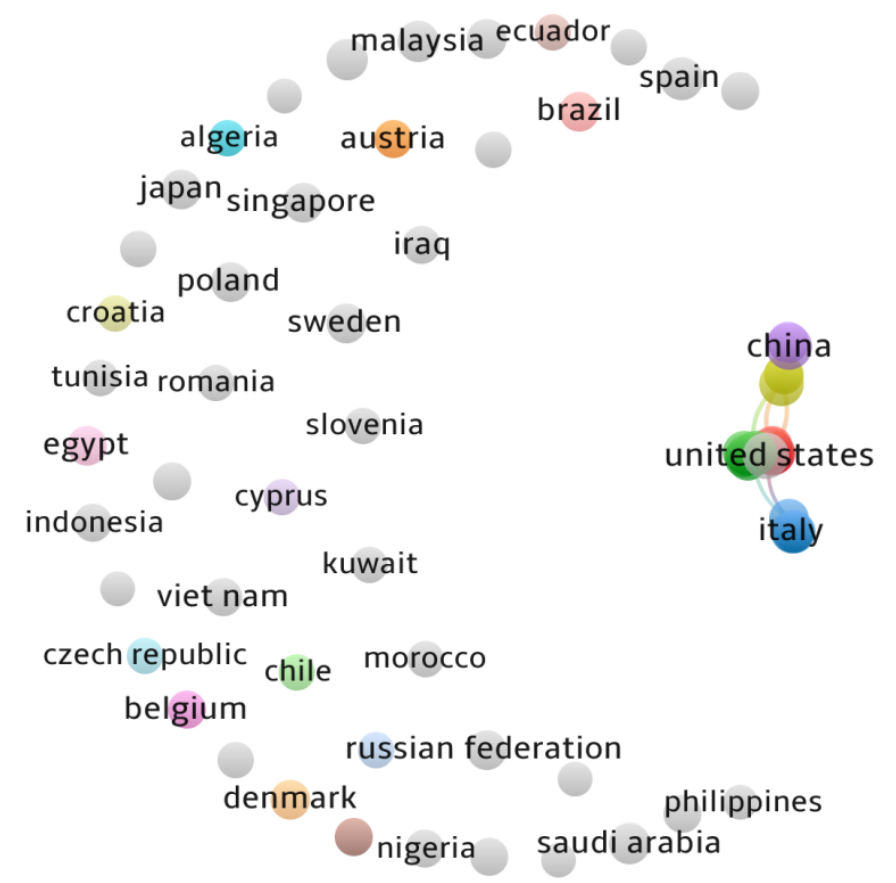


Figure 1 Geographical Cluster for literature study

The Literature study used bibliographic analysis for the study. Articles on wall temperature, thermal effect, energy efficiency, regression models, and artificial neural networks have been collected. The clustering has been visualized using VOS viewer software based on papers published geographically in the year 2021. The comprehensive analysis has 52 clusters with different citation counts, and table 1 shows the top 5 links.

Table 1 Descriptive statements of cluster analysis

\begin{tabular}{|c|l|}
\hline Sl.No & \multicolumn{1}{|c|}{ Cluster Details } \\
\hline 1 & $\begin{array}{l}\text { The 1st cluster has six links (i.e.) Articles from Australia, France, Germany, } \\
\text { Ireland, Norway, UAE had collaborated, and the citations for each article } \\
\text { published are incredibly high. }\end{array}$ \\
\hline 2 & $\begin{array}{l}\text { The 2nd cluster has five links (i.e.) Articles from India, Netherlands, New } \\
\text { Zealand, South Korea, Taiwan had collaborated, and the citations for each } \\
\text { article published are high. }\end{array}$ \\
\hline 3 & $\begin{array}{l}\text { The 3rd cluster has four links (i.e.) Articles from Finland, Iran, Italy, Portugal } \\
\text { had collaborated, and the citations for each article published are moderate. }\end{array}$ \\
\hline 5 & $\begin{array}{l}\text { The 4th cluster has three links (i.e.) Articles from Greece, Qatar, the United } \\
\text { Kingdom had collaborated, and the citations for each article published are Low. }\end{array}$ \\
\hline collaborated, and the citations for each article published are Shallow.
\end{tabular}

According to the authors, humans spend most of their lives within buildings, implying a high need for energy for varied activities (Grygierek and Ferdyn-Grygierek 2018). The need for indoor comfortableness and the energy consumption of a building depend directly on the geographical area, building type, orientation, binder or insulating material of the structure, etc. Numerous research has been carried out with precision for several decades to explore the impact of environmental variables on the thermal behaviour of buildings (Yumrutaş, Ünsal, and Kanoğlu 2005)(Kolokotsa et al. 2019). The heat transfer method involves the building gaining or losing heat energy from the exterior to the interior via the building envelope and roof. Outside, ambient temperature and relative humidity have a critical influence on the passage of heat through a building's face, hence its residents' health (Givoni et al. 2003). Near-surface temperature appears to be a significant issue, particularly for structures that receive direct star radiation. For instance, despite the surrounding inside temperature being at 
reasonably high, occupants feel cold because of chilling walls or windows. Similarly, heated surfaces may keep occupants warmer than the ambient air temperature (Childs, Courville, and Bates 1983).

All meteorological variables have not been considered to make life more comfortable for humans (Sarker et al. 2020). It is significantly noted that the flow of heat through a wall can be a thermal energy loss of that building; However, the difference between external and indoor temperatures is just the primary driver of heat flow. The most significant contributor to the heat flow in the building is the increase of heat via the opaque surface of the building. It is critical to have total control over the building's internal and external temperatures to generate reliable findings for judging its thermal behaviour (Haarhoff and Mathews 2006). The impact of wind speed on the absorption of heat flow; on the outer surfaces of the structure was investigated. The outcomes recommend that wind speed significantly impacts the absorption of heat transition on the outside phase of the building (Yadav and Berwal 2021). The thermal performance of the exterior is also influenced by the wall's orientation (Coley and Kershaw 2010).

As a result, researchers tend to consider the complete front of the building in this analysis. (Catalina, Virgone, and Blanco 2008) They examined many models to find the best working model between a house's heating demand and the five independent variables: the form factor, the window-to-surface ratio, the climate, and the building's time constant. The researcher also conducted a comparative investigation of the artificial neural network model in other disciplines (Ottenbacher et al. 2001). When researchers (Tsilingiris 2004) compared the artificial neural network model with the regression model, they discovered that the ANN outperforms the straightforward linear regression approach. It demonstrates that the quasi (neural) model significantly has more accuracy than generic models with economical cost than the additional squared error (Dodier and Henze 2004).

The literature indicates a strong link between the external climate variables and the building's inner thermal comfort behaviour (Lord 2006). Unlike earlier research, this contrasts an alternative specific model, the Poisson regression model, with an artificial neural model (using SPSS v.23) for predicting the structure's exterior wall/roof temperature. This work aims to compile the most helpful information on predicting the temperature of a building's outer walls using multivariate analysis, to provide a standard guideline for futuristic studies. In addition, the research work's goal is to determine the relationship and relevance between weather conditions and the building's out-of-sight wall temperature by examining each model for the best findings. 


\section{CHARACTERISTICS OF MULTIPLE LINEAR REGRESSION MODEL}

Multiple linear regression is a type of multivariate analysis that uses an extended linear model to model data sets. It's also known as a log-linear model performed during constructing a contingency table (Edwards, Holt, and Harris 2000). This is a widely utilized approach for regression worldwide, as well as in Asian countries. These models have been proven to provide a more accurate representation of the procedure and variability in the distribution of error structure based on the information requirements. The approach also improves applied mathematics management for the likelihood analysis of a wide range of unfavourable factors. In regression models, the following probability density function equation (1) is used to find the probability value y on ith unit:

$\mathrm{P}(\mathrm{X}=\mathrm{x})=\frac{\mathrm{e}^{-\mu \mathrm{i} \mu \mathrm{i}^{\mathrm{y}}}}{\mathrm{x} !}$

where $\mu \mathrm{i}$ is the regression parameter for dependent unit $\mathrm{i}$, which is equal to the predicted mean $\mathrm{x}$ and determined using functional

$\mu \mathrm{i}=\mathrm{e}^{\sum \beta \mathrm{iyi}}$

Where $\beta \mathrm{i}$ are coefficients and yi are the various explanatory factors. Because the regression distribution presupposes that the mean equals the variance, these models can't manage overand under-dispersion. Low sample means might harm their performance, resulting in unjust outcomes in case studies with small samples (Lord 2006). Because these circumstances are frequently encountered in data, academics have attempted to address them by defining several types of error terms.

\section{CHARACTERISTICS OF ARTIFICIAL NEURAL NETWORK (ANN) MODEL}

Artificial Neural Networks are computer-based, non-parametric, self-adaptive models based primarily on human neurons developed in the 1960s (Aarthy Reddy, Balasubramanian, and Selvam 2020). Predictive neural models are instrumental in applications involving complex data, such as fraud detection, credit evaluation, and pattern recognition. As depicted in the perceptron design in Figure 2, a neural model consists of an input layer (independent variables), a middle (hidden) layer, and an output layer (dependent variables). Each network has only one input and output layer. To acquire the more significant work model, the hidden layers can be changed. The summation and activation functions are contained in the hidden layer. The input layers process the data using a part before sending the signal to the output layer. Weights represent the strength of a nerve cell, whereas bias allows the activation curve 
to be varied. The process of coaching a neural network is similar to that of fitting a regression model, and it is carried out using standard applied mathematics techniques (Edwards, Holt, and Harris 2000). The neural model will forecast the most critical variable using a normalized importance approach like the regression model. Fitting a relapse model is proportional to getting a neuronal system ready. It's done by iteratively changing masses to the point where the system's yields have a negligible chance of being incorrect. Typically, very modest irregular loads are introduced gradually. Compared to other regression models, the forecast values provided by the Neural Network Model are less vulnerable to variation, according to an applied mathematics examination of the remaining values (Zhai and Previtali 2010).

\section{DATA SOURCE}

The information was gathered from the literature's (Coley and Kershaw 2010) (Yadav and Berwal 2021) (Fumo and Rafe Biswas 2015) (Wangpattarapong et al. 2008), where the external wall temperature, relative humidity and wind speed are taken as primary parameters in their study. The ambient temperature of the building's north, south, east and west side external facades is monitored at regular intervals, and data on meteorological parameters are collected. The data set is made up of 100 readings for each wall. When dealing with multiple models, the data set is frequently divided into two parts: training (model construction) and testing the model's performance. The random division method was utilized to test and train the various models employed in this investigation. The arbitrary division approach divides the overall data set into two portions at random. As a whole, 75 data points were utilized for training the data, and the rest 25 data points were used to test the models for each wall in the current study. Both models were investigated using test data utilizing three statistical measures: mean absolute error (MAE), Root Mean Square Error (RMSE), and R-squared.

\section{SELECTION OF VARIABLES}

In general, the link between dependent and explanatory factors was used to choose dependent and explanatory variables in temperature prediction models of building external walls. The actual outside temperature of the wall is utilized as the dependent variable, and three meteorological parameters are employed as explanatory variables: ambient temperature, relative humidity and wind direction. Table 2 shows the summary statistics for these factors.

Table 2 Statistics of test variables for weather factors

\begin{tabular}{|c|c|c|c|c|c|c|}
\hline Wall & S. no & Parameters & Symbol & $\begin{array}{c}\text { Minimum } \\
\text { values }\end{array}$ & $\begin{array}{c}\text { Maximum } \\
\text { Values }\end{array}$ & Mean \\
\hline East & 1 & Average Temperature ( C) & Y1 & 10.9 & 39.8 & 28.70 \\
\hline
\end{tabular}




\begin{tabular}{|c|c|c|c|c|c|c|}
\hline & 2 & Relative Humidity (\%) & $\mathrm{Y} 2$ & 0.32 & 0.71 & 0.47 \\
\hline & 3 & Wind Speed $(\mathrm{m} / \mathrm{s})$ & Y3 & 0.30 & 8.45 & 3.68 \\
\hline \multirow{3}{*}{ West } & 1 & Average Temperature ( $\mathrm{C}$ ) & Y1 & 12.5 & 42.5 & 30.13 \\
\hline & 2 & Relative Humidity (\%) & $\mathrm{Y} 2$ & 0.53 & 0.62 & 0.56 \\
\hline & 3 & Wind Speed $(\mathrm{m} / \mathrm{s})$ & Y3 & 0.47 & 8.26 & 4.50 \\
\hline \multirow{3}{*}{ North } & 1 & Average Temperature ( $\mathrm{C}$ ) & Y1 & 11.2 & 40.2 & 29.16 \\
\hline & 2 & Relative Humidity (\%) & $\mathrm{Y} 2$ & 0.54 & 0.84 & 0.54 \\
\hline & 3 & Wind Speed $(\mathrm{m} / \mathrm{s})$ & $\mathrm{Y3}$ & 0.24 & 9.23 & 3.47 \\
\hline \multirow{3}{*}{ South } & 1 & Average Temperature ( $\mathrm{C}$ ) & $\mathrm{Y} 1$ & 11.8 & 38 & 26.37 \\
\hline & 2 & Relative Humidity (\%) & $\mathrm{Y} 2$ & 0.42 & 0.69 & 0.39 \\
\hline & 3 & Wind Speed $(\mathrm{m} / \mathrm{s})$ & Y3 & 0.37 & 7.87 & 3.90 \\
\hline
\end{tabular}

\section{STATISTICAL ANALYSIS OF REGRESSION MODEL}

The backward pass method was used to create the regression model. The association between completely separate freelance variables was discovered in this model (Krishnaraj et al. 2019). All three variables were chosen at the start. Those factors that were not viewed as necessary (Pearson's correlation value $>0.85$ and p 0.05 demonstrates a significant relationship at a 95\% confidence level) were eliminated, so when the BIC and AICC pointers were significantly reduced, the most critical factors were lost at intervals throughout the equation. The regression model (which included all input variables) was created, and labour quality was tested (Singh, Sachdeva, and Pal 2016). The table shows that the changing ambient temperature is the main critical factor affecting the temperature difference of all the walls (Asadi, Amiri, and Mottahedi 2014). Wind direction is a variable that has a significant impact on the east and west walls. Varied quantitative relationship primarily affects the north wall, while the factor wind speed only impacts the temperature of the west wall. The outcome of factors reflects the comparing change in wall temperature costs for a one-unit change in the educational variable's worthwhile maintaining with any remaining constant parameters. It is clear from Table 1 that the temperature of the walls is entirely different from the average temperature. Only the north wall temperature has a variable quantitative relationship. Wind direction has a negative association with east and west wall temperature (Haarhoff and Mathews 2006). A 3D plot has been drawn using the matplotlib library in Python. There are four plots developed, each for one direction. From the plots, it is evident that the North direction has more deviation from its mean. 


\section{STATISTICAL ANALYSIS OF ARTIFICIAL NEURAL NETWORK}

The artificial neural network was analyzed in python. The ANN built consists of 2 hidden layers. The first hidden layer consists of 16 neurons, and the second consists of 12 neurons. The neural network takes an input shape of 3 based on the data set provided. The output is a softmax function over four outcomes as provided by the data set. The model has been built using the Keras library in Python. The accuracy obtained is around 45\%. The "categorical cross-entropy" is used as the network's loss function and the "adam" optimizer. The software chooses the most effective match based on the number of nodes created in the hidden layer. Coaching and testing datasets were prepared similarly to the regression model by selecting subsets of the data in various ways. Again, the research work shows that ambient temperature is an essential factor of the walls. The relative humidity is the next important factor, then finally the wind direction.

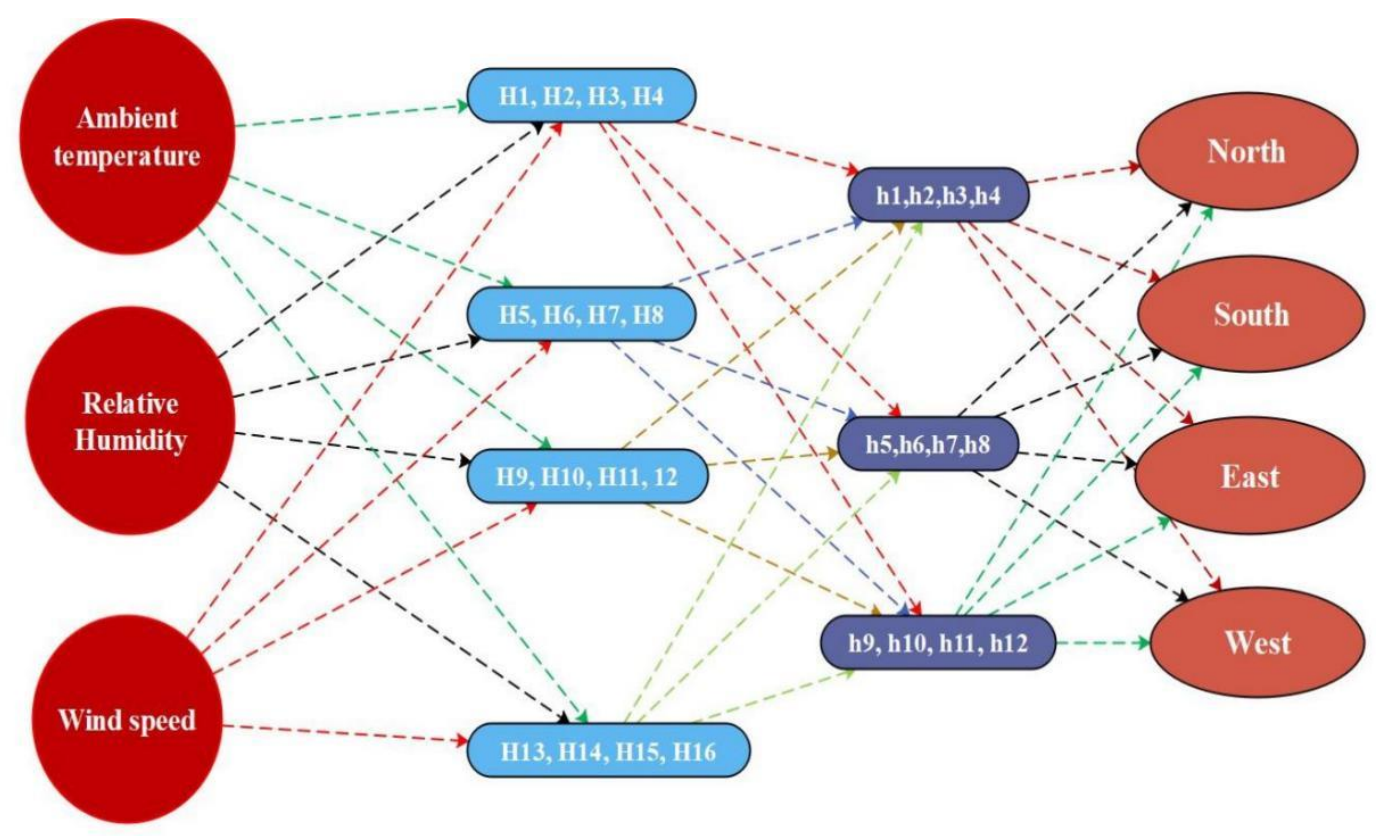

Figure 2 Structure of Artificial Neural Network

Table 3 Relative importance of various variables in Artificial Neural Network Model.

\begin{tabular}{|c|c|c|c|c|}
\hline \multirow[b]{2}{*}{ Direction } & \multirow[b]{2}{*}{ Error } & \multicolumn{3}{|c|}{ Climatic Specifications } \\
\hline & & $\begin{array}{c}\text { Average } \\
\text { temperature }{ }^{\circ} \mathrm{C} \text { Y1 }\end{array}$ & $\begin{array}{c}\text { Rh (Relative } \\
\text { Humidity) \% Y2 }\end{array}$ & $\begin{array}{c}\text { Ws m/s (Wind } \\
\text { speed) Y3 }\end{array}$ \\
\hline North & 0.55 & 29.16 & 53.8 & 3.47 \\
\hline South & 0.89 & 26.37 & 39.4 & 3.90 \\
\hline
\end{tabular}




\begin{tabular}{|l|l|l|l|l|} 
East & 0.12 & 28.70 & 46.9 & 3.68 \\
\hline West & 0.19 & 30.13 & 56.1 & 4.50 \\
\hline
\end{tabular}

COMPARATIVE STATISTICS OF MODELS

The test data was utilized to analyze the performance of each model concerning its Mean Absolute Error (MAE) values, Root Mean Square Error (RMSE) values and R-squared value. Table 3 shows the statistical analysis of the regression model and artificial neural network model in comparison. Table 4 shows that the artificial neural network model delivers results better than the regression model for all four direction walls. Figure 3 shows the actual vs fore-casted exterior wall temperature graphs for each direction. The results of this figure imply that the Neural model matches the test data much better.

Table 4 Statistical analysis of artificial neural network and regression models.

\begin{tabular}{|l|c|c|c|c|c|c|c|c|}
\hline \multirow{2}{*}{$\begin{array}{c}\text { Statistical } \\
\text { Analysis }\end{array}$} & \multicolumn{2}{|c|}{$\begin{array}{c}\text { North } \\
\text { Direction Wall }\end{array}$} & \multicolumn{2}{c|}{$\begin{array}{c}\text { South } \\
\text { Direction Wall }\end{array}$} & \multicolumn{2}{c|}{$\begin{array}{c}\text { East Direction } \\
\text { Wall }\end{array}$} & $\begin{array}{c}\text { West Direction } \\
\text { Wall }\end{array}$ \\
\cline { 2 - 10 } & MLR & ANN & MLR & ANN & MLR & ANN & MLR & ANN \\
\hline R Squared & 0.75 & 0.86 & 0.87 & 0.95 & 0.69 & 0.87 & 0.64 & 0.84 \\
\hline RMSE & 0.99 & 0.91 & 0.92 & 0.74 & 1.43 & 1.25 & 1.30 & 0.82 \\
\hline MAE & 3.81 & 3.14 & 3.42 & 3.31 & 6.19 & 4.80 & 5.76 & 3.45 \\
\hline
\end{tabular}

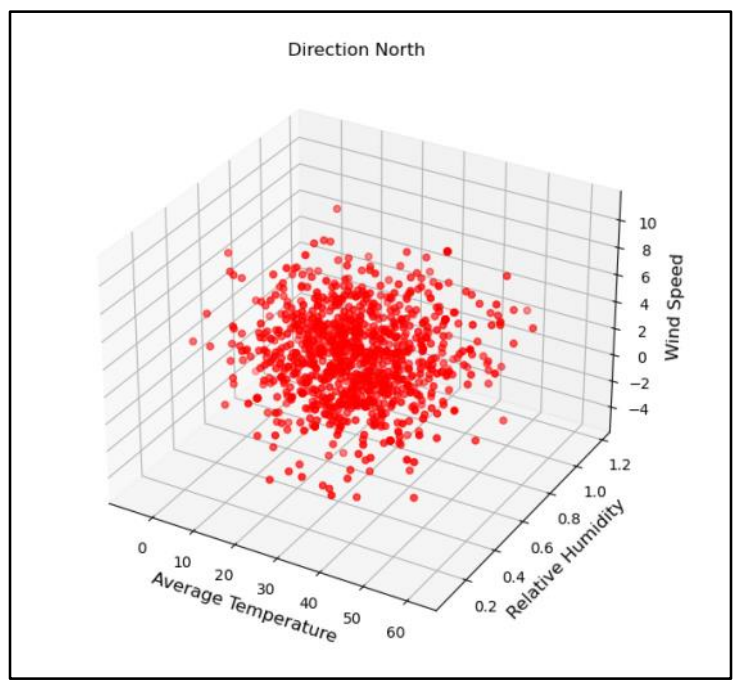

(a)

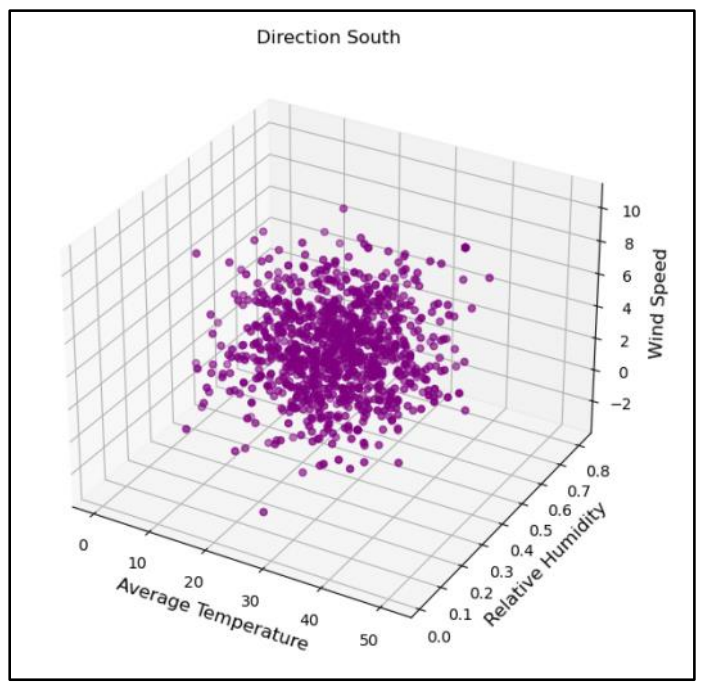

(b) 


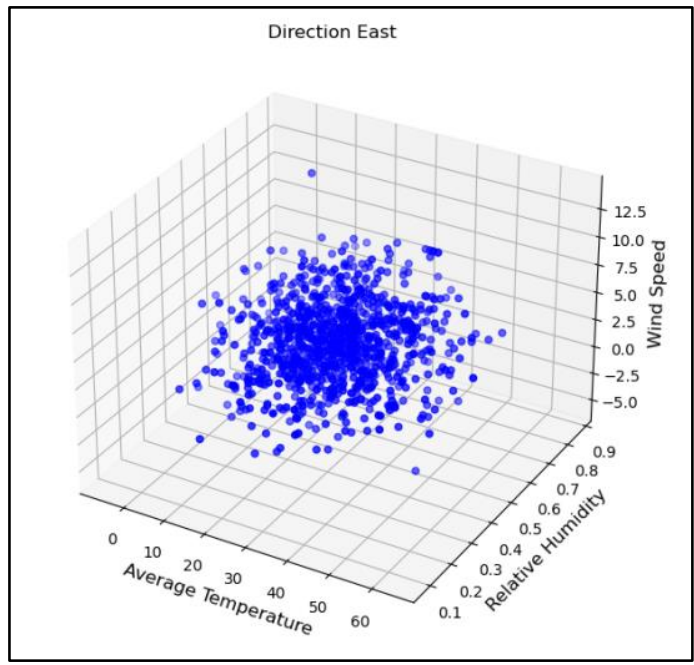

(c)

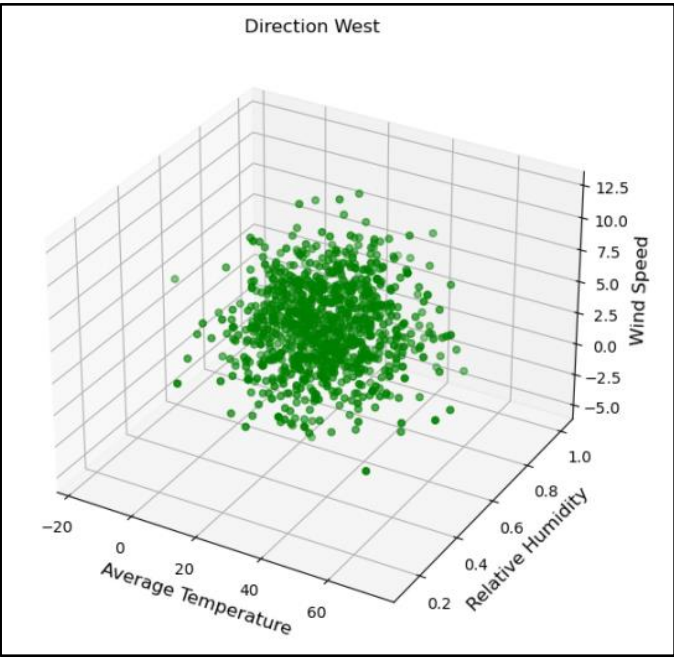

(d)

Figure 3 Predicted temperature in (a) North, (b) South, (c) East (d) West direction based on ambient temperature, wind speed and relative humidity.

\section{CONCLUSION}

To establish an empirical correlation between meteorological parameters and the temperature of the exterior wall, the regression model and the artificial neural network were used. These models' outputs are frequently used to forecast outside temperature using outdoor weather information. Each of the models' outcomes is equivalent and significant. Two models demonstrate that the average temperature is a necessary variable which is $29.16^{\circ} \mathrm{C}$ in the north, $26.37^{\circ} \mathrm{C}$ in the south, $28.70^{\circ} \mathrm{C}$ in the east, $30.13^{\circ} \mathrm{C}$ in west direction. It should be taken into account in a prominent place on the entire building front, hence influencing the thermal comfort behaviour of the whole structure. On some facades, wind speed is also a significant opposing component that affects the outside temperature of the building. The wind speed is $3.47 \mathrm{~m} / \mathrm{s}$ in the north, $3.90 \mathrm{~m} / \mathrm{s}$ in the south, $3.68 \mathrm{~m} / \mathrm{s}$ in the east and $4.50 \mathrm{~m} / \mathrm{s}$ in the west. Even though the neural model has a more extensive range than the regression models, this study only utilizes it as a backup model because it has not been mathematically specified. In the regression model, one tends to find the constant values, allowing one to forecast the temperature of the outer wall accurately. The artificial neural network model used in this method can't measure the impacts of the variable elements on the wall temperature. There is $45 \%$ of accuracy from the artificial neural network. This analysis aids designers and engineers in comprehending the importance of environmental parameters for the different facades of a structure so that the thermal behaviour of the building can be enhanced by providing appropriate insulating materials and energy-saving alternatives based on specific requirements. 


\section{REFERENCE}

Aarthy Reddy, R., M. Balasubramanian, and Gopinath Selvam. 2020. "Analysis the Effect of Chromosome and Generation Count on Genetic Algorithm in Construction Projects: A Case Study.” IOP Conference Series: Materials Science and Engineering 912 (6). https://doi.org/10.1088/1757-899X/912/6/062056.

Arnfield, A. John. 2003. "Two Decades of Urban Climate Research: A Review of Turbulence, Exchanges of Energy and Water, and the Urban Heat Island." International Journal of Climatology 23 (1): 1-26. https://doi.org/10.1002/joc.859.

Asadi, Somayeh, Shideh Shams Amiri, and Mohammad Mottahedi. 2014. "On the Development of Multi-Linear Regression Analysis to Assess Energy Consumption in the Early Stages of Building Design." Energy and Buildings 85: 246-55. https://doi.org/10.1016/j.enbuild.2014.07.096.

Catalina, Tiberiu, Joseph Virgone, and Eric Blanco. 2008. "Development and Validation of Regression Models to Predict Monthly Heating Demand for Residential Buildings." Energy and Buildings 40 (10): 1825-32. https://doi.org/10.1016/j.enbuild.2008.04.001.

Chan, A. L.S. 2011. "Developing Future Hourly Weather Files for Studying the Impact of Climate Change on Building Energy Performance in Hong Kong." Energy and Buildings 43 (10): 2860-68. https://doi.org/10.1016/j.enbuild.2011.07.003.

Childs, K.W., G.E. Courville, and E. L. Bates. 1983. "Thermal Mass Assessment: An Explanation of the Mechanisms by Which Building Mass Influences Heating and Cooling Energy Requirements." Ornl, no. ORNL/CON-97: 86. http://web.ornl.gov/info/reports/1983/3445605519980.pdf.

Coley, David, and Tristan Kershaw. 2010. "Changes in Internal Temperatures within the Built Environment as a Response to a Changing Climate.” Building and Environment 45 (1): 89-93. https://doi.org/10.1016/j.buildenv.2009.05.009.

Dodier, Robert H., and Gregor P. Henze. 2004. "Statistical Analysis of Neural Networks as Applied to Building Energy Prediction." Journal of Solar Energy Engineering, Transactions of the ASME 126 (1): 592-600. https://doi.org/10.1115/1.1637640.

Edwards, David J., Gary D. Holt, and Frank C. Harris. 2000. "Comparative Analysis between the Multilayer Perceptron 'neural Network' and Multiple Regression Analysis for Predicting Construction Plant Maintenance Costs." Journal of Quality in Maintenance Engineering 6 (1): 45-60. https://doi.org/10.1108/13552510010371376.

Fumo, Nelson, and M. A. Rafe Biswas. 2015. "Regression Analysis for Prediction of Residential Energy Consumption." Renewable and Sustainable Energy Reviews 47: 
332-43. https://doi.org/10.1016/j.rser.2015.03.035.

Givoni, Baruch, Mikiko Noguchi, Hadas Saaroni, Oded Pochter, Yaron Yaakov, Noa Feller, and Stefan Becker. 2003. "Outdoor Comfort Research Issues." Energy and Buildings 35 (1): 77-86. https://doi.org/10.1016/S0378-7788(02)00082-8.

Grygierek, Krzysztof, and Joanna Ferdyn-Grygierek. 2018. "Multi-Objectives Optimization of Ventilation Controllers for Passive Cooling in Residential Buildings." Sensors (Switzerland) 18 (4). https://doi.org/10.3390/s18041144.

Haarhoff, J., and E. H. Mathews. 2006. "A Monte Carlo Method for Thermal Building Simulation." Energy and Buildings $38 \quad$ (12): 1395-99. https://doi.org/10.1016/j.enbuild.2006.01.009.

Kolokotsa, D., V. Vagias, L. Fytraki, and K. Oungrinis. 2019. "Energy Analysis of Zero Energy Schools: The Case Study of Child's Asylum in Greece.” Advances in Building Energy Research 13 (2): 193-204. https://doi.org/10.1080/17512549.2018.1488612.

Krishnaraj, L., V. R.Prasath Kumar, M. Balasubramanian, Naveen Kumar, and T. Shyamala. 2019. "Futuristic Evaluation of Building Energy Simulation Model with Comparison of Conventional Villas." International Journal of Construction Management 0 (0): 1-10. https://doi.org/10.1080/15623599.2019.1579968.

Lord, Dominique. 2006. "Modeling Motor Vehicle Crashes Using Poisson-Gamma Models: Examining the Effects of Low Sample Mean Values and Small Sample Size on the Estimation of the Fixed Dispersion Parameter." Accident Analysis and Prevention 38 (4): 751-66. https://doi.org/10.1016/j.aap.2006.02.001.

McMichael, A. J., and E. Lindgren. 2011. "Climate Change: Present and Future Risks to Health, and Necessary Responses." Journal of Internal Medicine 270 (5): 401-13. https://doi.org/10.1111/j.1365-2796.2011.02415.x.

Nikolopoulou, Marialena, Nick Baker, and Koen Steemers. 2001. "Thermal Comfort in Outdoor Urban Spaces: Understanding the Human Parameter." Solar Energy 70 (3): 227-35. https://doi.org/10.1016/S0038-092X(00)00093-1.

Ottenbacher, Kenneth J., Pam M. Smith, Sandra B. Illig, Richard T. Linn, Roger C. Fiedler, and Carl V. Granger. 2001. "Comparison of Logistic Regression and Neural Networks to Predict Rehospitalization in Patients with Stroke." Journal of Clinical Epidemiology 54 (11): 1159-65. https://doi.org/10.1016/S0895-4356(01)00395-X.

Sarker, Ankur, Fan Yao, Haiying Shen, Huiying Zhao, Haoran Zhu, Haroon Lone, Laura Barnes, Brad Campbell, and Mitchel Rosen. 2020. "Deep Learning Based Prediction towards Designing a Smart Building Assistant System.” Proceedings - 2020 
IEEE 17th International Conference on Mobile Ad Hoc and Smart Systems, MASS 2020, 202-10. https://doi.org/10.1109/MASS50613.2020.00034.

Singh, Gyanendra, S. N. Sachdeva, and Mahesh Pal. 2016. "M5 Model Tree Based Predictive Modeling of Road Accidents on Non-Urban Sections of Highways in India." Accident Analysis and Prevention 108-17. https://doi.org/10.1016/j.aap.2016.08.004.

Spagnolo, Jennifer, and Richard de Dear. 2003. "A Field Study of Thermal Comfort in Outdoor and Semi-Outdoor Environments in Subtropical Sydney Australia." Building and Environment 38 (5): 721-38. https://doi.org/10.1016/S0360-1323(02)00209-3.

Tsilingiris, P. T. 2004. "On the Thermal Time Constant of Structural Walls." Applied Thermal Engineering $\quad 24 \quad$ (5-6): 743-57. https://doi.org/10.1016/j.applthermaleng.2003.10.015.

Verbeke, Stijn, and Amaryllis Audenaert. 2018. “Thermal Inertia in Buildings: A Review of Impacts across Climate and Building Use." Renewable and Sustainable Energy Reviews 82 (August 2017): 2300-2318. https://doi.org/10.1016/j.rser.2017.08.083.

Wangpattarapong, Kiattiporn, Somchai Maneewan, Nipon Ketjoy, and Wattanapong Rakwichian. 2008. "The Impacts of Climatic and Economic Factors on Residential Electricity Consumption of Bangkok Metropolis.” Energy and Buildings 40 (8): 141925. https://doi.org/10.1016/j.enbuild.2008.01.006.

Yadav, Manisha, and Anil K. Berwal. 2021. "Predicting Building Wall Temperature in Composite Climate Using Regression Models: A Comparative Study." Materials Today: Proceedings 45 (xxxx): 5052-58. https://doi.org/10.1016/j.matpr.2021.01.567.

Yumrutaş, Recep, Mazhar Ünsal, and Mehmet Kanoğlu. 2005. "Periodic Solution of Transient Heat Flow through Multilayer Walls and Flat Roofs by Complex Finite Fourier Transform Technique." Building and Environment 40 (8): 1117-25. https://doi.org/10.1016/j.buildenv.2004.09.005.

Zhai, Zhiqiang (John), and Jonathan M. Previtali. 2010. "Ancient Vernacular Architecture: Characteristics Categorization and Energy Performance Evaluation." Energy and Buildings 42 (3): 357-65. https://doi.org/10.1016/j.enbuild.2009.10.002. 